\title{
Explanatory style in youth self-harm: an Indian qualitative study to inform intervention design
}

\author{
Shilpa Aggarwal 이, ${ }^{1}$ George Patton, ${ }^{2}$ Deepika Bahl, ${ }^{1}$ Nilesh Shah, ${ }^{3}$ Michael Berk, \\ Vikram Patel $\left.\right|^{5}$
}

\begin{abstract}
Additional material is published online only. To view please visit the journal online (http://dx.doi.org/10.1136/ ebmental-2020-300159).
\end{abstract}

Department of Mental Health and Non-Communicable Diseases, Public Health

Foundation of India, New Delhi, Delhi, India

${ }^{2}$ Department of Adolescent Health, Murdoch Childrens Research Institute, Parkville, Victoria, Australia

${ }^{3}$ Department of Psychiatry, Sion Hospital, Mumbai, Maharashtra, India

${ }^{4}$ Department of Psychiatry, Deakin University School of Medicine, Geelong, Victoria, Australia

${ }^{5}$ Department of Global Health and Social Medicine, Harvard University T H Chan School of Public Health, Boston, Massachusetts, USA

Correspondence to Dr Shilpa Aggarwal, Public Health Foundation of India, New Delhi, Delhi, India; shilpazq@ gmail.com

Received 1 May 2020 Revised 27 May 2020

Accepted 1 June 2020

Published Online First

10 July 2020

\section{ABSTRACT \\ Background There are very few studies that have} examined the effectiveness of psychological interventions (PIs) that have been developed and tested in highincome countries to reduce self-harm in low and middleincome countries.

Objective To evaluate the perspectives and explanatory styles of youth with self-harm and their caregivers to inform the design of an evidence based PI in a nonWestern cultural setting. An additional objective was to suggest ways of integrating local practices and traditions to enhance its acceptability.

Methods We conducted 15 in-depth qualitative interviews with youth with self-harm and four interviews with the caregivers in the psychiatry department of a tertiary hospital located in Mumbai, India. Data were analysed using phenomenological thematic analysis. Findings Five themes were uncovered: (i) contextual factors related to self-harm including interpersonal factors, intrapersonal factors and socio-cultural factors; (ii) formulation and current feelings about the attempt (iii) family members and friends as the perceived supports and deterrents for future self-harm attempts; (iv) treatment related experiences with counselling, in-patient and outpatient treatment and barriers to treatment; and (v) coping strategies. Recommendations for key areas of adaptation include therapist adaptation, content adaptation to accommodate for cultural considerations and broader social context. Gender based socio-cultural norms, beliefs and stigma attached to selfharm need to be specifically addressed in South Asian setting. Interpersonal conflicts are the most common triggers.

Conclusion and clinical implications To our knowledge this is the first study in the South Asian context evaluating explanatory styles of youth with selfharm and their caregivers to inform the design of an intervention to ensure its cultural congruence. Cultural adaptation of an evidence based $\mathrm{PI}$ results in competent delivery and ensures best results in diverse ethno-cultural populations

\section{BACKGROUND}

Globally, 78\% of all completed suicides occur in low and middle-income countries (LMICs). ${ }^{1}$ There are very few studies that have examined the effectiveness of psychological interventions (PIs) that have been developed and tested in high-income countries to reduce self-harm in LMICs. ${ }^{2}$ Many of these interventions do not adequately take into account client's unique cultural values and norms. ${ }^{3}$ The nature of the problem is such that any intervention for self-harm or suicide must address the associated social, and individual determinants for a significant impact. ${ }^{4}$

Furthermore, the role of cultural factors in psychotherapy adaptations has been increasingly identified. $^{5}$ Cultural adaptation of an evidence based PI results in competent delivery and ensures best results in diverse ethno-cultural populations. ${ }^{3}$ Such an adaptation should take into account cultural norms and values elicited by an evaluation of the explanatory style of the clients and family members for which the PI is being adapted. ${ }^{36}$ Bernal et al suggest such adaptations to be the way forward to provide effective psychotherapies to all individuals contextualised in terms of cultural values, language, socioeconomic status and gender. ${ }^{3}$

Explanatory style is defined as 'notions about an episode of sickness and its treatment that are employed by all those engaged in the clinical process (clients, families, practitioners)'. ${ }^{7}$ We conducted the current qualitative study as part of a larger mixed method study to inform the design of a PI for self-harm in youth. The larger study consisted of smaller studies: in-depth interviews to explore the explanatory styles of youth who have self-harmed; review of effectiveness of self-harm interventions in youth; focused group discussions with stakeholders including youth who have self-harmed and mental health professionals working with this population; integrating strategies identified using smaller studies into a modular-intervention; and pilot testing the intervention to test the acceptability and feasibility. The qualitative methods were deemed most appropriate to explore the explanatory style of youth with self-harm to optimise the content, structure and delivery of a PI for self-harm. ${ }^{8}$

\section{OBJECTIVE}

The objective of this qualitative study was to evaluate the perspective of clients and family members and their explanatory styles around self-harm to inform the design of an evidence based intervention for self-harm in youth in a non-Western cultural setting.

\section{METHODS}

The study consisted of 15 in-depth qualitative interviews with youth and four interviews with the caregivers of youth presenting to the psychiatry department of a major public sector tertiary hospital located in Mumbai, India following a self-harm attempt. We recruited participants from 15 years to 24 years of age to ensure inclusion of 
mid-adolescence and late-adolescence, a point of higher prevalence for self-harm, ${ }^{9}$ and the most vulnerable age range for death due to suicide, especially in women. ${ }^{10}{ }^{11}$ Suicide is the second leading cause of death in 15-29 years of age in India ${ }^{12}$ and the second most common cause of death among 10-24 year olds worldwide after road traffic accidents. ${ }^{13}{ }^{14}$ As age increases, selfharm rates decline. ${ }^{13}$

In India, adulthood is considered to begin at 18 years of age. Caregivers of participants under 18 years of age were invited for the interviews to get a comprehensive understanding of the circumstances of self-harm as well as the explanatory styles of caregivers to ensure we captured sufficient information relevant to this key age group. The role of caregivers in help-seeking behaviour and outcome of any PI is likely to be greater in younger clients. The sampling was purposeful with an aim to ensure representation across both genders, through the age range for the study and include different experiences and frequencies of self-harm, selected on the basis of repetition of self-harm (never, once, more than once).

The in-depth interviews were conducted by the first author using two interview guides, one each for youth with self-harm and caregivers (online supplementary appendix). The interviews covered four domains: details of the self-harm episode; history and course of self-harm; experience of treatment received following self-harm and process and content related perspectives for an intervention for self-harm. All the interviews were audio recorded after obtaining necessary written informed consent. We used the concept of data saturation as suggested by Saunders et al to gauge the total number of interviews. ${ }^{15}$ The number of interviews are consistent with the qualitative research conducted in the field of self-harm previously and similar to the experience of one of the authors (VP) of conducting qualitative research in Indian setting. ${ }^{16}$

The audio recordings were transcribed verbatim for the analysis. Data were analysed using phenomenological thematic analysis. ${ }^{17}$ The approach to understand the phenomena was inductive with the themes identified linked to the data, without an attempt to fit the data in a pre-existing coding framework. ${ }^{18}$ Two authors (SA, DB) independently coded the transcripts after familiarising themselves with the transcripts, noting observations and descriptive comments to reflect initial understanding of the content. The subthemes were identified from the data to capture the essential qualities of the interview and consisted of summaries and examples. Subthemes with a common point of reference were unified into themes. The labels were finalised after a comparison of the themes and discussion about any differences. A spread sheet with a data matrix was used to facilitate a comparison between subgroups (male and female, marital status) and within subgroups (age and gender).

\section{RESULTS}

The duration of the in-depth interviews ranged from $45 \mathrm{~min}$ to $90 \mathrm{~min}$. There were 10 female and 5 male participants in the study. Four participants were under 18 years of age. The details of the participants are listed in table 1 . Although as many as 10 participants had harmed themselves in the past, only one had a history of past hospital admission following self-harm. The numbered themes in the last column in table 1 correspond to tables 2 and 3.

Five themes were identified from the participants' interviews. (1) Contextual factors related to self-harm, formulation and current feelings. (2) Formulation and current feelings about the

Table 1 Details of the participants

\begin{tabular}{|c|c|c|c|c|c|c|c|c|c|}
\hline & $\begin{array}{l}\text { Age } \\
\text { (years) }\end{array}$ & Gender & Marital status & $\begin{array}{l}\text { Education } \\
\text { employment }\end{array}$ & Living with & Mental illness diagnosis & $\begin{array}{l}\text { Number of } \\
\text { attempts }\end{array}$ & $\begin{array}{l}\text { Number of } \\
\text { hospital } \\
\text { admissions }\end{array}$ & $\begin{array}{l}\text { Themes identified } \\
\text { (from tables } 2 \text { and } 3 \text { ) }\end{array}$ \\
\hline 1. & 23 & M & Unmarried & Graduate & Parents and sibling & No diagnosis & 2 & 1 & Ia, Ie, If, IIa, IIb, Ile, IIIa, IVa, IVc, IVd, Vb \\
\hline 2. & 17 & M & Unmarried & School grade 10 dropout & Parents & $\begin{array}{l}\text { Cluster B personality traits, } \\
\text { conduct disorder }\end{array}$ & 1 & 1 & $\begin{array}{l}\text { Ia, Ic, Id, If, Ila, IIb, IIf, IIlb, IVa, IVe, Vb } \\
\text { CG: Ib, Ic, Ilc, IId, Ile, IIg, IIIb, IVa, IVb, IVc }\end{array}$ \\
\hline 3. & 17 & $\mathrm{~F}$ & Unmarried & In school & Parents & $\begin{array}{l}\text { Premenstrual dysphoric } \\
\text { disorder }\end{array}$ & 1 & 0 & $\begin{array}{l}\text { Id, Ile, IIIa, IIIb, IVd, Vc } \\
\text { CG: Id, IIb, Ile, IIIc, IVb }\end{array}$ \\
\hline 4. & 15 & $\mathrm{~F}$ & Unmarried & In school & $\begin{array}{l}\text { In residential } \\
\text { accommodation }\end{array}$ & $\begin{array}{l}\text { Oppositional defiant disorder, } \\
\text { major depressive disorder }\end{array}$ & 1 & 0 & $\begin{array}{l}\text { Ia, Ic, Id, Ile, Va } \\
\text { CG: Ia, Ib, Ila, IIc, IIg, IIIa, IIIc, IVd }\end{array}$ \\
\hline 5. & 16 & $\mathrm{~F}$ & Unmarried & School grade 9 dropout & Parents and siblings & $\begin{array}{l}\text { Cluster B personality traits, } \\
\text { learning disability }\end{array}$ & 1 & 1 & $\begin{array}{l}\text { Ia, Id, IId, Ile, IIIa, IVa, IVe, Va } \\
\text { CG: Ia, IId, IIg, IIIb, IVb, IVd }\end{array}$ \\
\hline 6. & 19 & $\mathrm{~F}$ & Unmarried & School grade 11 dropout & Parents and siblings & $\begin{array}{l}\text { Conversion disorder, } \\
\text { generalised anxiety disorder }\end{array}$ & 4 & 1 & $\begin{array}{l}\text { Ia, Id, Ila, IIc, IIb, IId, Ile, IIla, IVa, IVb, IVc, } \\
\text { IVe, IVf, IVg, Va, Vb, Vc, Vd }\end{array}$ \\
\hline 7. & 24 & M & Married & $\begin{array}{l}\text { Graduate } \\
\text { Works as peon }\end{array}$ & $\begin{array}{l}\text { Disabled father, } \\
\text { mother and wife }\end{array}$ & Cluster B personality traits & 2 & 1 & $\begin{array}{l}\text { Id, Ie, If, Ila, Ile, IIg, IIIa, IIIb, IVa, IVb, } \\
\text { Vb, Vc, Vd }\end{array}$ \\
\hline 8. & 23 & M & Engaged & $\begin{array}{l}\text { Graduate } \\
\text { Unemployed }\end{array}$ & Father & $\begin{array}{l}\text { Obsessive compulsive disorder, } \\
\text { major depressive disorder }\end{array}$ & 2 & 0 & Ie, If, Ile, IIg, IIla, IVb, IVc, IVd, Vb, Vc, Ve, \\
\hline 9. & 18 & $\mathrm{~F}$ & Unmarried & In college & Parents, sibling & No diagnosis & 1 & 1 & Id, IId, Ile, IVa, IVd, IVg, IVe \\
\hline 10. & 19 & $\mathrm{~F}$ & $\begin{array}{l}\text { Married, } \\
\text { estranged from husband }\end{array}$ & $\begin{array}{l}\text { School grade } 8 \text { drop-out } \\
\text { Works as personal caretaker }\end{array}$ & Mother & $\begin{array}{l}\text { Major depressive disorder, } \\
\text { post-traumatic disorder }\end{array}$ & 2 & 1 & Ia, li, Ilb, IId, IIf, IVa, IVd \\
\hline 11. & 20 & $\mathrm{~F}$ & Engaged & Finished grade 12 & Parents & No diagnosis & 1 & 1 & Ia, Ib, Id, IIc, Ile, IIg, IIIb, IVa, IVe, IVf \\
\hline 12. & 22 & $\mathrm{~F}$ & Unmarried & Studying in college & Parents & $\begin{array}{l}\text { Alcohol dependence, post- } \\
\text { traumatic stress disorder }\end{array}$ & 5 & 3 & $\begin{array}{l}\text { Ia, Id, Ig, IIlb, Ild, Ile, IIIb, IIIb, IVa, IVb, } \\
\text { IVd, IVe, Vb, Vf }\end{array}$ \\
\hline 13. & 22 & M & Unmarried & Shopkeeper & Roommate & $\begin{array}{l}\text { Alcohol dependence, cluster B } \\
\text { personality traits }\end{array}$ & 3 & 1 & Ia, Id, Ie, IIb, IIIb, IVa, IVc, Vf \\
\hline 14. & 20 & $\mathrm{~F}$ & Divorced & Grade 9 dropout & $\begin{array}{l}\text { Brother and sister- } \\
\text { in-law }\end{array}$ & No diagnosis & 1 & 1 & $\begin{array}{l}\text { la, Ib, Id, Ig, Ih, Ilb, IId, Ile, Ilg, IIlb, } \\
\text { IVa, IVe }\end{array}$ \\
\hline 15. & 22 & $\mathrm{~F}$ & Unmarried & $\begin{array}{l}\text { Graduate, enrolled in a } \\
\text { computer course }\end{array}$ & Parents & $\begin{array}{l}\text { Recurrent depressive disorder, } \\
\text { social phobia }\end{array}$ & 2 & 1 & Ib, le, Ig, li, Ila, Ilb, Ile, IIf, IIlb, IVa \\
\hline
\end{tabular}




\begin{tabular}{|c|c|}
\hline \multicolumn{2}{|c|}{ I. Contextual factors related to self-harm. } \\
\hline Interpersonal factors & $\begin{array}{l}\text { a. Interpersonal conflict with family member, } \\
\text { acquaintance, workmate, friend. } \\
\text { b. To repair the relationship. } \\
\text { c. Exposure to recent self-harm by someone known/ } \\
\text { close to client. }\end{array}$ \\
\hline Intrapersonal factors & $\begin{array}{l}\text { a. Inability to control emotions such as anger. } \\
\text { b. Overwhelming sense of hopelessness/despair. }\end{array}$ \\
\hline Socio-cultural factors & $\begin{array}{l}\text { a. Financial stressors, employment loss. } \\
\text { b. Stigma due to perceived promiscuous/sexually } \\
\text { provocative behaviour. } \\
\text { c. Stigma due to infertility. } \\
\text { d. Fear of losing face/societal respect. }\end{array}$ \\
\hline \multicolumn{2}{|c|}{ II. Formulation and current feelings about the attempt. } \\
\hline Formulation & $\begin{array}{l}\text { a. Normalising past self-harm attempt as an option to } \\
\text { deal with stressor. } \\
\text { b. Sense of problems being extreme and } \\
\text { circumstances exceptional. } \\
\text { c. Significant stigma related to people who self-harm } \\
\text { and difficulty in accepting self as part of that } \\
\text { group. } \\
\text { d. Sense of social isolation. }\end{array}$ \\
\hline Current feelings & $\begin{array}{l}\text { a. Remorse about attempt, self-harm a mistake and } \\
\text { an act of betrayal towards family members. } \\
\text { b. Regret about failed attempt. } \\
\text { c. Considering failed attempt as second chance at } \\
\text { life-reflecting on attempt and resolutions about } \\
\text { future. }\end{array}$ \\
\hline \multicolumn{2}{|c|}{ III. Perceived supports, and deterrents. } \\
\hline \multicolumn{2}{|c|}{$\begin{array}{l}\text { a. Family members and friends main support. } \\
\text { b. Parental concern and familial relationships as deterrent towards future atte }\end{array}$} \\
\hline \multicolumn{2}{|c|}{$\begin{array}{l}\text { IV. Treatment related experiences around self-harm attempt, help-seeking and } \\
\text { potential barriers to help-seeking. }\end{array}$} \\
\hline \multirow{2}{*}{\multicolumn{2}{|c|}{$\begin{array}{l}\text { a. In-patient hospital treatment as less useful, psychiatry assessment and } \\
\text { management more helpful. } \\
\text { b. Treatment experiences prior to the attempt unhelpful as clients did not fee } \\
\text { and understood. } \\
\text { c. Professional support by doctor considered more useful than by just counse } \\
\text { d. Counselling useful if tailored to needs. } \\
\text { e. Impulsive nature of self-harm leading to doubt about usefulness of counse } \\
\text { f. Beliefs about people who harm themselves a barrier to help-seeking. } \\
\text { g. Talking to stranger a barrier for counselling. } \\
\text { v. Coping strategies found useful to allay self-harm thoughts. }\end{array}$}} \\
\hline & \\
\hline \multicolumn{2}{|c|}{$\begin{array}{l}\text { a. Distraction Strategies useful. } \\
\text { b. Socialising with friends/going outside of } \mathrm{h} \\
\text { considered as supportive timeout strategy } \\
\text { c. Confiding in family members supportive. } \\
\text { d. Exercise as a helpful strategy. } \\
\text { e. Religious beliefs as protective. } \\
\text { f. Substance use for emotional regulation. }\end{array}$} \\
\hline
\end{tabular}

attempt (3) Perceived supports, deterrents. (4) Treatment related experiences around self-harm attempt, help-seeking and potential barriers to help-seeking. (5) Coping strategies found useful to allay self-harm thoughts (table 2).

\section{Contextual factors related to self-harm, formulation and current feelings}

The contextual factors consisted of three categories, interpersonal; intrapersonal; and socio-cultural factors.

\section{Interpersonal factors}

The interpersonal factors included conflict with another person, self-harm in an attempt to influence other person's behaviour or contact with someone who had harmed themselves. An
Table 3 Themes and subthemes from caregivers' interviews
I. Contextual factors related to self-harm.
a. Interpersonal conflict with family member, acquaintance, workmate, friend.
b. Exposure to recent self-harm by someone known.
c. Due to a religious vow.
d. Overwhelming physical pain.

II. Formulation and current feelings about the attempt.

$\begin{array}{ll}\text { Formulation } & \text { a. Self-harm as an act to get attention. } \\ & \text { b. Sense of physical problem being extreme and circumstances } \\ & \text { exceptional. } \\ & \text { c. Self-harm as an option to deal with stressors as learnt from } \\ & \text { others who have acted similarly. } \\ \text { Current feelings } & \text { a. Shameful act causing embarrassment to the family. } \\ & \begin{array}{l}\text { b. Feelings of helplessness and guilt. } \\ \text { c. Fear of repetition. }\end{array}\end{array}$

III. Treatment related experiences around a self-harm attempt, help-seeking and barriers to help-seeking.

a. Treatment experiences prior to attempt unhelpful.

b. Counselling to help them make better choices.

c. Counselling may not be effective due to the reasons for self-harm interfering with the benefits.

IV. Strategies to help them in future.

a. By monitoring their company closely.

b. By letting them know how much their act has affected the family.

c. By getting professional help such as counselling.

d. By following the doctor's recommendations.

underlying inability to resolve the situation using any other option or considering self-harm to be the best possible option was a common subtheme in all the cases.

There was a distinct difference in the interpersonal factors between the two genders. Relationship difficulties and conflict in a marital unit, with a fiancé or a boyfriend was present in four female participants. A conflict with a friend (15-year-old participant) or with one of the parents preceded the self-harm attempt in three female participants. According to a female participant lack of trust of her fiancé led her to resort to selfharm. "He [fiancé] was having doubts about me... what if I get attracted towards someone else." (Female, 20 years). Three participants harmed themselves when the relationship broke down. "I thought after taking phenyl either I will die or he [fiancé] will realise that I can kill myself for him..." (Female, 20 years).

A complex interplay of interpersonal and sociocultural factors contributed to self-harm in two instances. A female participant reported a significant fear of losing face in the society following failure of a relationship. "Now if we are not together there is no point in my living... I have had experiences [referring to physical relationship and medical termination of pregnancy] that an unmarried girl should not have had." (Female, 22 years).

The interpersonal conflict with a family member occurred in context of unemployment in two male participants whereas a conflict with a workmate precipitated a self-harm attempt in the third instance. "Younger sister joined in saying 'You don't work outside, earn money or contribute in the housework'." (Male, 23 years).

The youngest male (17 years) and female participants (15 years) had a close contact with someone who had self-harmed prior to the attempt. "He had seen 4-5 people eating rat-kill [local rat poison brand] in our neighbourhood recently. Two of them died." (Caregiver of male, 17 years) (table 3). 
Intrapersonal factors

Overriding emotions and inability to regulate their emotional state prior to self-harm was the main intrapersonal factor. Most of them were extremely angry and some experienced an overwhelming sense of hopelessness/despair. Despair was experienced by up to four males as compared with a single female. "I inserted 'sua' [needle] in my wrist...I can't control anger. Other people stop me but at that time there was no one to stop." (Male, 22 years).

\section{Socio-cultural factors}

Socio-cultural contextual factors were different for both genders. Employment related and financial factors played an important role in self-harm in four out of five male participants. These factors were compounded by the interpersonal difficulties and longstanding conflict leading to despair.

On the other hand, shame and stigma due to perceived flouting of social norms about feminine role in society, was an important subtheme identified from the five female participants' interviews. Three of them reported being humiliated by family members for perceived promiscuous or sexually provocative behaviour. "Then he [father] told me that I wear short clothes and dance nude (in a pub) like a prostitute. I replied back stating I was not a prostitute." (Female, 22 years).

A single female participant was taking medical help for infertility that led to strained relationship with the husband. Another female participant attributed self-harm to inability to access the child after separation from husband and a sense of shame and guilt about leaving the child. "My son is with the in-laws, they don't allow me to meet him. I must die as I have left my child to get a better life." (Female, 19 years).

\section{Formulation and current feelings about the attempt}

Most participants formulated the attempt as an error of judgement due to overwhelming emotions and feelings of utter despair and hopelessness. Up to 12 participants expressed remorse about the self-harm. They considered the act a mistake mainly in consideration of their family members and friends. "I was thinking about my wife, my parents... if I go, who will take care of them. It was a mistake." (Male, 24 years).

Two female participants going through marriage related problems expressed a sense of isolation and a lack of friendship that could have possibly averted the situation. Both of them reported an inability to maintain friendships following their marriage. "I feel the need to share my difficulties at such times with a friend who can understand it." (Female, 23 years).

Four female and three male participants considered failed attempt as a second chance at life and suggested they would use the opportunity to reflect on their life and set goals for future. "This gave me a chance to think about wanting to live my life without my husband." (Female, 20 years).

Three participants, two female and one male, reported feeling disappointed about the failed attempt. The psychopathology was much worse in these cases as compared with the rest. In the male participants there were significant personality vulnerabilities and the other two suffered from post-traumatic stress disorder and recurrent depressive disorder respectively.

\section{Perceived supports, and deterrents for self-harm}

Family members and friends were identified as the main support following the self-harm by up to six participants.

Seven participants reported the parental concern and family relationships as a significant deterrent towards any such future attempt. "Third time I will definitely not do it because of my dad." (Male, 24 years).

In as many as eight participants, no clear deterrent could be identified. An acknowledgement of the distress that family might experience due to repeat self-harm did not act as a deterrent in a few participants. "As I said... I know my family will suffer more than me... But I am not able to go on like this..." (Female, 22 years).

\section{Treatment related experiences around self-harm attempt,} help-seeking and potential barriers to help-seeking

Many of the participants (n-12) were admitted in the in-patient unit of the medicine department following the self-harm attempt. The median length of in-patient stay was 3 days. None of them found the treatment received in the in-patient unit of any psychological help.

Referral and subsequent assessment in the psychiatry outpatient department was reported to be supportive by eight participants. "The ward where I was admitted was of no use. In the outpatient department, I felt understood by the doctor who was making helpful suggestions." (Male, 24 years).

Two male participants had received counselling prior to the recent most self-harm attempt but none of them found it helpful. "It should have been more helpful [counselling session]. I didn't feel any better. So I decided to go to the doctor and told him I would go 'mental'. He prescribed me a few medicines, didn't make me understand anything." (Male, 24 years).

Six participants (including the two who had received counselling prior to self-harm) reported that counselling could be useful only when they feel understood, heard and it is tailored to their needs. "The counsellor kept suggesting a lot of things. I am not sure she understood what I was going through." (Male 23 years). Three male participants and a female participant were of the view that counselling received from the doctor was of more use as compared with that received by the counsellor. "What the doctor says is not equal to another person saying as it carries more weightage." (Male, 23 years).

Perceptions of self-harm as something done on the spur of the moment and therefore, could not be predicted or gotten help for, was a significant barrier to help seeking in seven cases. "I am not sure if it [counselling] would have helped me when I harmed myself...it happened so suddenly." (Female, 18 years).

Two female participants felt that self-harm is done by a specific set of people and didn't consider themselves a part of that group preventing them from sharing their distress prior to the attempt with anyone. "Wrong people do so. People who are in love and break-up... I don't want to be thought of as one of them." (Female, 19 years).

Talking to a stranger was considered to be a barrier for counselling by two female participants. "I don't talk to any outsider, only my family members. I wouldn't want to talk to a stranger..." (Female, 19 years).

\section{Coping strategies found useful to allay self-harm thoughts} There were differences in the coping strategies used by both genders. Males preferred going out with friends as compared with females who preferred to distract themselves using music or other household activities. Four out of five male participants reported socialising with friends as a useful timeout strategy. Three female participants reported using distraction strategies such as listening to music, and getting involved in household activities such as cooking useful. 
Physical exercise was reported to be helpful by a male participant whereas breathing exercises were found useful by a female participant.

Four participants identified confiding in family members about self-harm thoughts as helpful. The supportive actions of the family members in two of these cases were influenced by the involvement and information provided by the mental health professionals. "Then my mother told me to take deep breaths [breathing exercises taught by doctor]. I felt relaxed..." (Female, 19 years).

The presenting self-harm episodes in two participants who had used alcohol to allay self-harm thoughts in the past, happened in absence of any alcohol use. Religious beliefs and rituals such as praying were immensely useful for a male participant whose father was a priest. "I kept my belief in God and prayed diligently. Half of the thoughts to harm myself were gone..." (Male, 22 years).

\section{Themes and subthemes identified from caregivers' interviews}

The formulation of self-harm as an attention seeking act that brought a lot of shame on the family were additional subthemes that emerged from the caregivers' interviews (table 3). "She harmed herself to get attention from others...she has tried to scare other girls in the past by acting like a ghost. This could be similar to those acts..." (Caregiver of female, 15 years).

A sense of fear about repetition of act, feelings of helplessness and guilt and a sense of anger that the family experienced due to the act were other subthemes that were identified. Three caregivers reported using the impact of the act on their family to deter the clients from doing it again. Two caregivers felt that counselling may help the participants in making better choices than harming themselves in future. However, two other caregivers felt that counselling may not be of use as the purpose of self-harm was to get some immediate practical gains that counselling cannot offer.

\section{DISCUSSION}

We have reported findings of in-depth interviews of young people who presented to a tertiary hospital in a metropolitan city of a South Asian country following a self-harm attempt. The interviews explored the explanatory styles of participants to identify salient domains for cross-cultural adaptation of a PI. There are limited PIs that have been adapted for self-harm in South Asian setting and none that are specific to youth.

The steps to identify the areas for adaptation were based on previously used process-driven stage model for cultural adaptation of an evidence based family skills training programme. ${ }^{19}$ The steps were: identification of key domains to target (conflict resolution skills, emotional regulation skills, social network enhancement skills); determining realms where an adaptation would be helpful (therapist adaptation; content adaptation to integrate the cultural considerations; and provisions to take into consideration the broader social context); using available evidence to select the PIs with components that could potentially be adapted ; and identifying the ways in which specific PI components could incorporate the strategies to make them culturally consonant (table 4).

In the current study, majority of the participants reported having an unempathic and unhelpful experience during the in-patient admission following self-harm. The limited benefit experienced by two participants who received counselling highlights the importance of rapport, and shared goal setting. In these instances, the participants felt counsellor was keener to give advice rather than listening to them, understand their experiences and work on a collaborative plan. The intervention should allow for a therapist-client matching with the therapist having an awareness of local customs and possibly some shared experiences. Such a therapist challenging the stereotypes, prejudices and discriminatory behaviour associated with selfharm and gender based socio-cultural norms might be more acceptable to the clients. In a PI adaptation for depression, the therapist belongs to the same community and is well versed in the socio-cultural norms. ${ }^{620}$ Another subtheme that stood out was the faith that the participants showed in the medical professionals. Traditionally, medical professionals are highly respected and tend to be more directive in approach in this setting. ${ }^{21}$ Their involvement even if peripheral and in a supervisory role, might help in addressing some of the stigma associated with self-harm by influencing the explanatory styles of the clients and help gather a greater amount of conviction in the treatment process.

More importantly, the PI should take into account the traditional gender based social roles and it's perceived failure, resulting in distress. For example, an expectation from males to earn a living and support the household and women to behave in a certain way for them not to be perceived as sexually promiscuous. The stigma experienced by five female participants due to perceived promiscuous/sexually provocative behaviour, infertility and fear of losing societal respect contributed significantly to self-harm. In addition, these beliefs and gender based norms can influence the help-seeking behaviour and the responses of the caregivers. ${ }^{22}$ For example, psychological distress in the context of unemployment might be considered by the male client as well as the family members as unworthy of warranting any help. The negative beliefs about people who self-harm, interfered in timely help-seeking in two female participants. The intervention could have addressed these beliefs leading to proactive help-seeking.

The content of the PI could accommodate for the strategies that the person has used and found useful as well as other local practices such as meditation or religious rituals (where appropriate and acceptable) for a personalised approach to treatment. Longstanding conflict in family and interpersonal relationships with underlying deficits in coping skills acted as a trigger in majority of participants in the study. At the same time, familial relationships were identified as a main support in times of crisis and a deterrent for future attempts. This makes it important for the PI to address long-standing interpersonal conflicts as well as allow flexibility for an individualised therapy involving supports identified by the client.

There have been PI adaptations that have used scenarios, idioms and material resembling the client's situation and background resulting in enhanced cultural congruence. ${ }^{23}$ A PI with conflict resolution skills, emotional regulation skills as well as social network enhancement skills training would be able to cater to the domains identified by the qualitative interviews in the current study (table 2). Evidence based PIs such as problem solving therapy, interpersonal therapy, dialectical behaviour therapy have emotional regulation, problem solving and interpersonal conflict resolution skills training as part of the treatment package. ${ }^{24-26}$

Furthermore, going out with friends which constituted an important coping strategy for males was an important deficit acknowledged by a couple of female participants. PI with integrated social network planning and enhancement techniques could be especially useful for females in this context. 


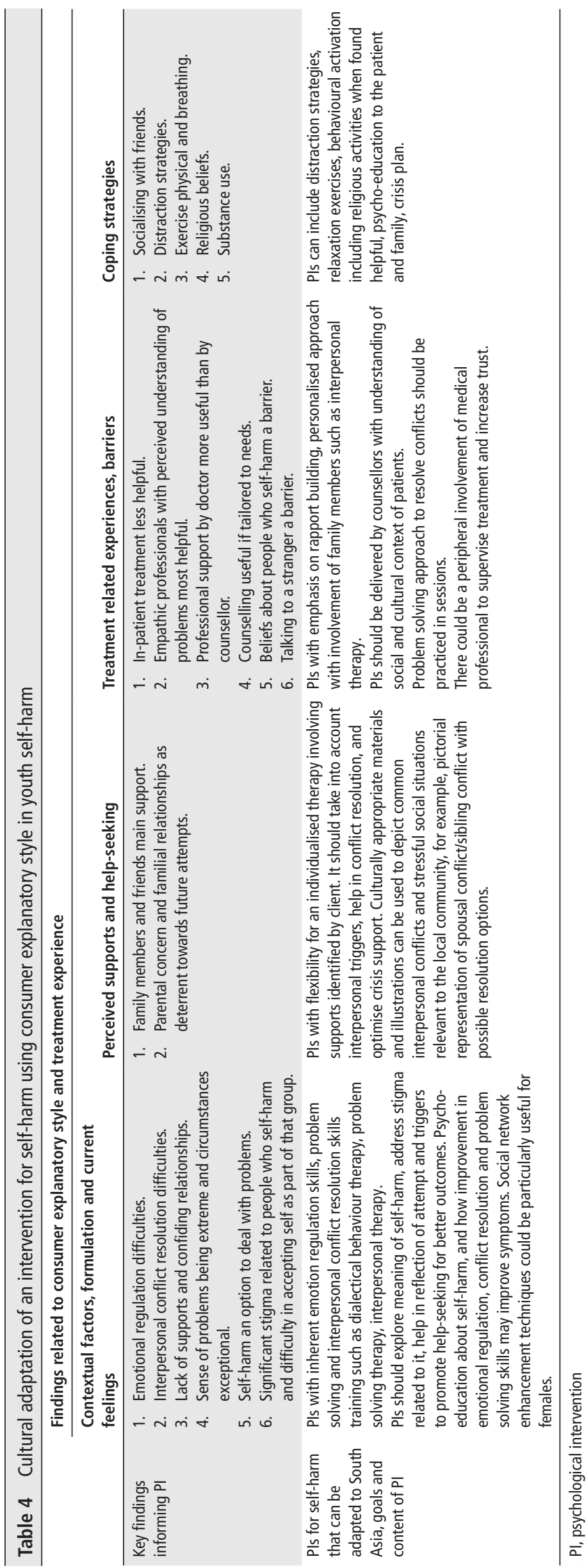




\section{CONCLUSION AND CLINICAL IMPLICATIONS}

To conclude, the qualitative study gives helpful directions for the design of a PI for self-harm in youth in a South Asian setting to ensure its cultural congruence. The adaptation could integrate local practices and traditions to enhance its acceptability with flexibility to allow for incorporation of the individual experiences leading to better clinical outcomes.

Contributors SA was involved in conceptualising and designing the study, analysis and drafting the manuscript. GP was involved in designing, analysis and drafting the manuscript. DB was involved in data analysis. NS was involved in designing and execution of the study. MB and VP were involved in guiding the study design, analysis and drafting the manuscript.

Funding This study was funded by The Wellcome Trust DBT India Alliance (IA/ CPHE/16/1/502664).

Competing interests None declared.

Patient consent for publication Not required.

Ethics approval The study was reviewed and approved by two ethics committees: Institutional Ethics Committee Lokmanya Tilak Municipal Medical College \& General Hospital, Mumbai-IEC/684118 and Institutional Ethics Committee Public Health Foundation of India, Gurgaon, Haryana IEC-366/17.

Provenance and peer review Not commissioned; externally peer reviewed.

Data availability statement No data are available.

ORCID iD

Shilpa Aggarwal http://orcid.org/0000-0002-8590-0846

\section{REFERENCES}

1 Bachmann S. Epidemiology of suicide and the psychiatric perspective. Int I Environ Res Public Health 2018;15:1425.

2 World Health Organization. Preventing suicide: a global imperative. World Health Organization, 2014.

3 Bernal G, Jiménez-Chafey MI, Domenech Rodríguez MM. Cultural adaptation of treatments: a resource for considering culture in evidence-based practice. Prof Psychol 2009:40:361-8.

4 Aggarwal S, Patton G, Reavley N, et al. Youth self-harm in low- and middle-income countries: systematic review of the risk and protective factors. Int I Soc Psychiatry 2017:63:359-75.

5 Castro FG, Barrera M, Holleran Steiker LK. Issues and challenges in the design of culturally adapted evidence-based interventions. Annu Rev Clin Psychol 2010;6:213-39
6 Chowdhary N, Jotheeswaran AT, Nadkarni A, et al. The methods and outcomes of cultural adaptations of psychological treatments for depressive disorders: a systematic review. Psychol Med 2014;44:1131-46.

7 Kleinman A, Eisenberg L, Good B. Culture, illness, and care: clinical lessons from anthropologic and cross-cultural research. Ann Intern Med 1978;88:251-8.

8 Mays N, Pope C. Assessing quality in qualitative research. Bmj 2000;320:50-2.

9 Patton GC, Hemphill SA, Beyers JM, et al. Pubertal stage and deliberate self-harm in adolescents. J Am Acad Child Adolesc Psychiatry 2007;46:508-14.

10 Soman CR, Safraj S, Kutty VR, et al. Suicide in South India: a community-based study in Kerala. Indian J Psychiatry 2009;51:261.

11 Aggarwal S. Suicide in India. Br Med Bull 2015;114:127-34.

12 Patel V, Ramasundarahettige C, Vijayakumar L, et al. Suicide mortality in India: a nationally representative survey. Lancet 2012;379:2343-51.

13 Hawton K, Harriss L. Deliberate self-harm in young people: characteristics and subsequent mortality in a 20-year cohort of patients presenting to hospital. I Clin Psychiatry 2007.

14 Patton GC, Coffey C, Sawyer SM, et al. Global patterns of mortality in young people: a systematic analysis of population health data. Lancet 2009;374:881-92.

15 Saunders B, Sim J, Kingstone T, et al. Saturation in qualitative research: exploring its conceptualization and operationalization. Qual Quant 2018;52:1893-907.

16 Lachal J, Orri M, Sibeoni J, et al. Metasynthesis of youth suicidal behaviours: perspectives of youth, parents, and health care professionals. PLoS One 2015; 10:e0127359.

17 Lewis S. Qualitative inquiry and research design: choosing among five approaches. Health Promot Pract 2015;16:473-5.

18 Vaismoradi $\mathrm{M}$, Jones J, Turunen $\mathrm{H}$, et al. Theme development in qualitative content analysis and thematic analysis. J Nurs Educ Pract 2016;6:100-10.

19 Kumpfer KL, Pinyuchon M, Teixeira de Melo A, et al. Cultural adaptation process for international dissemination of the strengthening families program. Eval Health Prof 2008;31:226-39.

20 Paul S, Bhatia V. Doctor patient relationship: changing scenario in India. Asian Journal of Medical Sciences 2016;7:1-5.

21 Patel V, Weiss HA, Chowdhary N, et al. Lay health worker led intervention for depressive and anxiety disorders in India: impact on clinical and disability outcomes over 12 months. Br J Psychiatry 2011;199:459-66.

22 Keohane A, Richardson N. Negotiating gender norms to support men in psychological distress. Am J Mens Health 2018:12:160-71.

23 Ramaiya MK, Fiorillo D, Regmi U, et al. A cultural adaptation of dialectical behavior therapy in Nepal. Cogn Behav Pract 2017;24:428-44.

24 Hawton K, Witt KG, Salisbury TLT, et al. Psychosocial interventions for self-harm in adults. Cochrane Database of Systematic Reviews 2016;5.

25 Aggarwal S. Systemic family therapy is not superior to treatment as usual in preventing repeat self-harm in adolescents. Evid Based Ment Health 2019;22:e9.

26 Hawton K, Witt KG, Taylor Salisbury TL, et al. Interventions for self-harm in children and adolescents. Cochrane Database Syst Rev 2015;18. 